\title{
Risk Assessment of Drought in the Yangtze River Delta Based on Natural Disaster Risk Theory
}

\author{
Gaofeng Fan, ${ }^{1}$ Yong Zhang, ${ }^{2}$ Yue He, ${ }^{1}$ and Kuo Wang ${ }^{1}$ \\ ${ }^{1}$ Zhejiang Climate Center, Hangzhou 310017, China \\ ${ }^{2}$ Meteorological Observation Centre, China Meteorological Administration, Beijing 100081, China \\ Correspondence should be addressed to Yong Zhang; yzhang@cma.gov.cn
}

Received 13 January 2017; Revised 16 April 2017; Accepted 9 May 2017; Published 31 May 2017

Academic Editor: Yong Zhou

Copyright (c) 2017 Gaofeng Fan et al. This is an open access article distributed under the Creative Commons Attribution License, which permits unrestricted use, distribution, and reproduction in any medium, provided the original work is properly cited.

\begin{abstract}
The risk of drought in the Yangtze River Delta Region (YRDR) was assessed using the method of natural disaster risk assessment. Based on the index of disaster risk, the assessment results of risk elements such as drought hazard and vulnerability were calculated in the YRDR. The division of relative drought risk levels in the YRDR was produced at the scale of county (city, district) and township. The results indicated that the areas of highest hazard of drought are located in the northern area of the YRDR. Areas with the greatest vulnerability of drought included Shanghai, Jiaxing, Wuxi, and Hangzhou. The highest risks of drought were mainly distributed in the north of the YRDR; the proportion of slightly high and extremely high risk areas in Shanghai, Nantong, Zhenjiang, Yangzhou, and Taizhou (Jiangsu province) is over 95\%. The lowest-risk areas included the southeast coastal area of the YRDR, especially in Hangzhou, and Taizhou (Zhejiang province), where the proportion of slightly high and extremely high risk areas is below $5 \%$. Based on this drought risk assessment, it is critical to establish a drought assessment system including both guarding against and addressing drought.
\end{abstract}

\section{Introduction}

In its series of assessment reports, the IPCC noted that drought is the most common natural disaster in the world. According to estimates, global economic losses of $\$ 6-8$ billion per year are caused by drought. Not only are drought costs much higher than the costs of other meteorological disasters, but drought risk has also shown an increasing trend [1]. To confirm the impact of drought in the future, the governments of various countries have implemented large numbers of engineering-based and non-engineering-based disaster mitigation actions. However, mitigation actions generally involve adjusting huge capital investments or affect a wide range of social systems. Uninformed mitigation actions will inevitably lead to misuse of human, material, and financial resources, which is contrary to the original goal of mitigation. To avoid the blindness that can lead to misuse of resources, it is important to perform scientific and systematic analyses of disaster preparation, occurrence, and development $[2,3]$.
A conceptual framework, which emphasizes the combined role of hazard and vulnerability in defining risk, is used for the study [4]. Based on the framework, the relative drought level or the absolute risk is calculated for the purpose of disaster risk zoning and risk management $[5,6]$. Regarding techniques, some studies use information diffusion theory, GIS, and remote sensing techniques to identify the degrees and levels of drought risk, drought evaluation, or drought monitoring [7-9]. These studies of drought risk assessment have built a solid foundation.

There are two stages of research on drought risk assessment. The first stage (1990-2000) focused on responses to crisis and risk management awareness. Several global droughts triggered a new understanding of the harm of drought, as people began to realize that drought was associated with not only a natural process but also the measures taken to address such disasters. Investigating the factors that affect drought based on a summary of past disasters, scientists became aware of the existence of drought risk, recognized the role of some nonnatural factors in drought, and began 
taking the initiative to ascertain the effects of drought. Consciousness of risk management became stronger [10, 11]. The second stage (since 2001) has focused on the occurrence of drought and highlighted the role of nonnatural factors in its mitigation. With the deepening study of global climate change, people's awareness of risk became more and more intense and addressing future disaster risk became a subject of study [12]. A series of studies examined climate change and the development of drought, the vulnerability of drought, and the risk assessment methods of drought. Most of these studies were from a quantitative or semiquantitative perspective; they explored the laws of drought development and emphasized the roles of human society, the economy, and environment in the face of drought pressure and the response to drought. These studies also actively tested measures to address future drought risk [13-15].

The Yangtze River Delta Region (YRDR) is the alluvial delta by the Yangtze River and the Qiantang River, which covers 210 thousand square kilometers and includes the southeast of Jiangsu province (8 cities: Nanjing, Suzhou, Wuxi, Changzhou, Zhenjiang, Nantong, Yangzhou, and Taizhou), Shanghai, and the northeast of Zhejiang province (7 cities: Hangzhou, Ningbo, Huzhou, Jiaxing, Shaoxing, Zhoushan, and Taizhou). YRDR is one of the most developed areas in China, but drought has a huge impact on society in this region. Disaster risk assessment is an important way for scientifically and systematically analyzing disaster risk and is a key process in the formation of disaster prevention and mitigation policies. Therefore, it is critical to study the process of drought risk assessment.

\section{Data}

The data sources used for risk assessment and zoning of drought in the YRDR include basic geographic information data, social economic statistics, and basic meteorological observation data.

Basic geographic information data consists of 1:50000 basic geographic information pieces of data in the YRDR, including topography, water distribution, land use types, and administrative boundaries. These data are provided by the surveying and mapping department.

Meteorological observation data consists of meteorological data from 105 National Weather Stations in the YRDR from 1961 to 2014, including daily rainfall and temperature.

Social economic data consists of statistical yearbook data from counties in the YRDR from 2000 to 2014, including administrative region land area, arable land area, total population, rural population, GDP, agricultural output value, local fiscal expenditure, total power of agricultural machinery, and social welfare statistical indicators.

\section{Method}

3.1. Risk Assessment Model. From the view of the mechanism of natural disasters, the following conditions are necessary for disaster formation: first, factors inducing disasters, such as drought caused by long-term lack of rain, and second, vulnerability of disaster, composed of the disaster-forming
TABLE 1: Drought rank of MDCI.

\begin{tabular}{lcc}
\hline Rank & Drought grade & MDCI \\
\hline 1 & Normal or wet & $-0.6<\mathrm{MDCI}$ \\
2 & Light drought & $-1.2<\mathrm{MDCI} \leqslant-0.6$ \\
3 & Medium drought & $-1.8<\mathrm{MDCI} \leqslant-1.2$ \\
4 & Drought & $-2.4<\mathrm{MDCI} \leqslant-1.8$ \\
5 & Severe drought & $\mathrm{MDCI} \leqslant-2.4$ \\
\hline
\end{tabular}

environment and the disaster-bearing bodies. The disasterforming environment includes topography, water distribution, vegetation cover, and other factors. The disaster-forming environment enlarges or reduces the hazard factors. From the perspective of the disaster-bearing body, the disasterforming environment is an important factor in determining the vulnerability of the disaster-bearing body. The disasterbearing body, including population, economic, and other factors, and the quantity and space distribution of the disaster-prone environment determine the vulnerability of hazard-affected bodies in a drought [16-18]. Referring to the natural disaster risk index, the drought risk assessment model is established as follows [19]:

$$
\mathrm{RI}=\mathrm{HI} \times \mathrm{VI},
$$

where RI is the disaster risk, $\mathrm{HI}$ is the drought hazard, and VI is the drought vulnerability.

3.2. Drought Hazard Assessment. The drought hazard is the possibility of a certain intensity of drought, which is usually determined by the frequency and intensity of drought. The first step is to determine the index system, which can reasonably evaluate the severity of drought.

As the cause of drought is very complex and many factors are involved, many drought indicators are used for specific research purposes, so the drought index has different spatial and temporal scales [19]. Some indicators reflect drought that is related to various physical processes (such as soil moisture evaporation, surface runoff, and ground water replenishment) through the mechanism of drought research, which aims to improve the accuracy of predicting drought intensity and duration [20, 21]. Other drought indexes reflect the intensity and duration of drought using statistical methods of precipitation distribution [22, 23].

For real-time drought monitoring and early warnings, a drought index should be established which can not only accurately monitor drought occurrence, development, and termination but also match different seasons and regions. The Meteorological Drought Composite Index (MDCI) is used to diagnose drought hazard assessment. MDCI is the national drought monitoring standard of china [24]. MDCI is a comprehensive index based on Standardized Precipitation Index (SPI) and Relative Moisture Index (RMI):

$$
\mathrm{MDCI}=0.4 Z_{3}+0.8 M_{3}+0.4 Z_{9},
$$

where $Z_{3}$ and $Z_{9}$ represent the SPI for last 30 and 90 days, respectively, and $M_{3}$ is the RMI for last 30 days; computing method follows Shahid and Behrawan (2008) [19]. Using observational daily data, MDCI is calculated day by day and the drought rank is defined in Table 1. 
Define the regional drought hazard index (HI) as follows:

$$
\begin{aligned}
\mathrm{NH} & =0.095 D_{l}+0.160 D_{m}+0.278 D_{d}+0.467 D_{s} \\
\mathrm{HI} & =\frac{\sum \mathrm{NH}}{M},
\end{aligned}
$$

where the $\mathrm{NH}$ is for the annual regional drought index; $D_{l}, D_{m}, D_{d}$, and $D_{s}$ represent the days of occurrence at a single station for light drought, medium drought, drought, and severe drought, respectively. $\mathrm{HI}$ is the regional drought intensity index, $\sum \mathrm{NH}$ is the sum of the annual drought index, and $M$ is the total number of years.

3.3. Drought Vulnerability Assessment. Drought vulnerability is composed of the disaster-forming environment and disaster-bearing bodies [19]. The vulnerability of the disasterforming environment in the YRDR is analyzed mainly using its topographic features, water system distribution, and land use characteristics [11]. Generally speaking, areas at low altitude are less vulnerable to drought, and higher areas are relatively more vulnerable. In addition, there is a close relationship between drought and topography. If there is fluctuation in the terrain, surface runoff will be collected in the gully and will discharge, and thus drought occurs more easily. The river and reservoir have very important effects on water storage and irrigation areas. Thus, the distribution density of the river network is also an important factor that cannot be ignored when considering drought. The degree of drought in various types of land is different, and the impact of drought is greatest on arable land.

In the field of disaster risk, the administrative unit is usually regarded as the disaster-bearing body, and its vulnerability usually reflects its population structure, social economic structure, and other social statistical indicators [14]. The vulnerability of a disaster-bearing body is mainly determined by the number of disaster-bearing bodies; the vulnerable evaluation factors of a disaster-bearing body involve the ratio of the agricultural GDP accounted for in the total GDP, the proportion of the agricultural population, the average regional GDP, and the ratio of farm crop-sown areas accounted for in land area. The sum total of each factor is calculated after normalization.

Based on former analysis, drought vulnerability includes 7 factors: the topographic factors, the water system factors, different types of land, the ratio of the agricultural GDP accounted for in the total GDP, the proportion of the agricultural population, the average regional GDP, and the ratio of farm crop-sown areas accounted for in land area.

(1) The Topographic Factors. The topographic factors are calculated as standard deviations of terrain in the YRDR $[25,26]$, with the selected range of $100 \mathrm{~m} * 100 \mathrm{~m}(5 * 5$ pitch), by the Digital Elevation Model (DEM) with resolution of $25 \mathrm{~m}$ * $25 \mathrm{~m}$. The terrain vulnerability is shown in Table 2 .

(2) The Water System Factors. Two factors are considered as influencing factors in the vulnerability index of water system: the density of river network and the buffer of rivers and lakes $[25,26]$. Because of the high density of river network, the area
TABLE 2: Assignment table of terrain vulnerability.

\begin{tabular}{lcccc}
\hline $\begin{array}{l}\text { Terrain } \\
\text { elevation }(\mathrm{m})\end{array}$ & \multicolumn{4}{c}{$\begin{array}{c}\text { Topographic } \\
\text { standard deviation }\end{array}$} \\
& $0-10$ & $10-25$ & $25-50$ & $\geq 50$ \\
\hline$<100$ & 0.3 & 0.4 & 0.5 & 0.6 \\
$100-200$ & 0.4 & 0.5 & 0.6 & 0.7 \\
$200-500$ & 0.5 & 0.6 & 0.7 & 0.8 \\
$\geq 500$ & 0.6 & 0.7 & 0.8 & 0.9 \\
\hline
\end{tabular}

TABLE 3: Classification criteria for buffer widths and their susceptible index in different waters.

\begin{tabular}{lcc}
\hline \multirow{2}{*}{ Type of water } & \multicolumn{2}{c}{ Buffer width $(\mathrm{km}) /$ impact index } \\
& First level buffer & Second level buffer \\
\hline $0.1-1 \mathrm{~km}^{2}$ reservoir/lake & $0.5 / 0.3$ & $1 / 0.1$ \\
$1-10 \mathrm{~km}^{2}$ reservoir/lake & $2 / 0.35$ & $4 / 0.15$ \\
$10-100 \mathrm{~km}^{2}$ reservoir/lake & $3 / 0.4$ & $6 / 0.2$ \\
$>100 \mathrm{~km}^{2}$ reservoir/lake & $5 / 0.45$ & $9 / 0.25$ \\
First level river & $4 / 0.45$ & $8 / 0.25$ \\
Second level river & $3 / 0.35$ & $6 / 0.15$ \\
\hline
\end{tabular}

irrigation conditions are fine and the effects of the drought degree are light. By normalizing the river network density, the high density area is converted to low drought vulnerability. The river network density index is calculated, and the formula is as follows:

$$
\text { Den }=\frac{\left(X_{\max }-X\right)}{\left(X_{\max }-X_{\min }\right)},
$$

where Den is the river network density index, $X_{\max }$ is the maximum density of the river network, $X_{\min }$ is the minimal density of the river network, and $X$ represents the river network density.

For calculation of rivers and lakes' buffer, rivers are divided into primary rivers (such as the Yangtze River and Huaihe River) and secondary rivers, such as tributaries and other rivers. Lakes are divided into primary buffers and secondary buffers, with appropriate weights of vulnerability factors according to the water area; the principle is to use the maximum for the primary river and large bodies of water and the minimum for the secondary rivers and small bodies of water. Table 3 shows the width of different buffer zones and the corresponding impact index; when the index value is greater, the effect of drought risk is smaller.

The vulnerability of water system is calculated by a comprehensive evaluation method, such as the following formula:

$$
\mathrm{WF}=\operatorname{Den} *(1-\mathrm{Bu}),
$$

where WF represents the water system vulnerability index, Den is the river network density index, and $\mathrm{Bu}$ is the buffer vulnerability index.

(3) Different Types of Land. Different types of land use can reflect the distribution of social and economic value and 
TABLE 4: Weight of different land types for drought.

\begin{tabular}{ccccccc}
\hline & Cultivated land & Grassland & Woodland & Land for urban and rural residents & Wetlands and water bodies & Other \\
\hline Influence degree & 0.9 & 0.8 & 0.7 & 0.6 & 0.4 & 0.2 \\
\hline
\end{tabular}

natural ecological value. According to different types of social and natural values, a certain weight is applied based on vulnerability to drought (Table 4).

(4) Others. The ratio of the agricultural GDP accounted for in the total GDP, the proportion of the agricultural population, the average regional GDP, and the ratio of farm crop-sown areas accounted for in land area are four normalization factors calculated based on social and economic statistical data from each of the counties or districts.

The composite drought vulnerability index (VI) of the integrated layers is calculated by using the following formula:

$$
\mathrm{VI}=\frac{\mathrm{TF}+\mathrm{WF}+\mathrm{DF}+\mathrm{AF}+\mathrm{PF}+\mathrm{GF}+\mathrm{CF}}{7}
$$

where VI ratings are assigned to drought vulnerability; TF ratings are assigned to the topographic factors; WF ratings are assigned to the water system factors; DF ratings are assigned to different types of land; AF ratings are assigned to the ratio of the agricultural GDP accounted for in the total GDP; $\mathrm{PF}$ ratings are assigned to the proportion of the agricultural population; GF ratings are assigned to the average regional GDP; CF ratings are assigned to the ratio of farm crop-sown areas accounted for in land area.

3.4. Drought Risk Index Analysis. Based on formula (1) of the drought risk index, the drought hazard and vulnerability are calculated by the layer operation function of ArcGIS software; the drought risk index layer is obtained.

In the YRDR, the drought risk index is divided into five risk levels using natural break point classification in ArcGIS, extremely high, slightly high, medium, slightly low, and extremely low, to obtain the relative risk grade division of drought.

\section{Results}

The assessment of drought hazard over the Yangtze River Delta shows that the hazard distribution increased gradually from south to north in the YRDR (Figure 1), with the higher hazard region at the north of the Yangtze River and the lowest hazard region along the coast of Zhejiang province. Due to the complex topography and precipitation distribution, the hazard faced by islands is higher than other areas in Zhejiang province.

The vulnerability is generally higher in the southern part of the YRDR (Figure 2). Because the northern part of the YRDR is the Yangtze River estuary plain, the flat terrain, dense river network, and numerous lakes make this area's disaster-forming vulnerability low overall. In contrast, the southern part of the YRDR is a mountainous region, where higher terrain and a sparse river network enhance
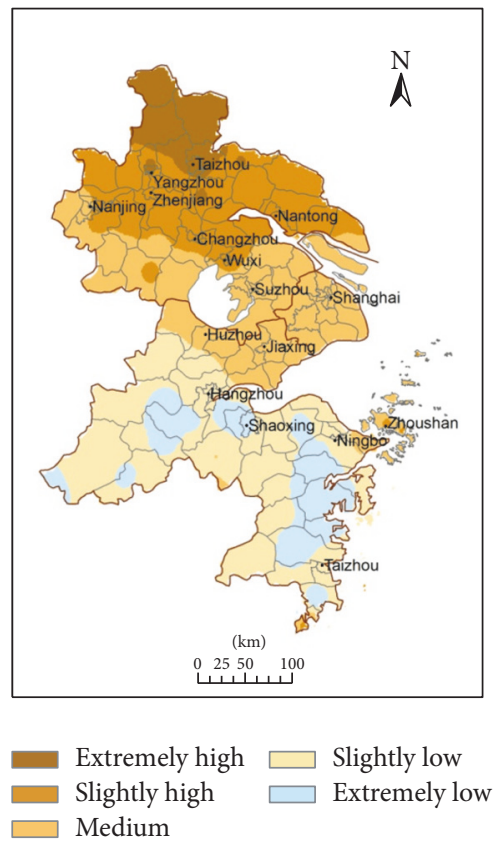

FIGURE 1: Distribution of drought hazard grades in the YRDR.

the drought hazard factor and increase vulnerability. Moreover, there are developed strong economies, high population densities, crop acreages, and a large number of industrial enterprises in the southern part of Jiangsu, Zhejiang, and Shanghai.

The results of calculating the grade division and relative risk index of drought in the YRDR are shown in Figure 3. The extremely high risk areas are mainly concentrated in the northern part of the YRDR, including Taizhou (Jiangsu province), Yangzhou, and most parts of Nantong. The slightly high risk areas are concentrated in Changzhou, Suzhou, Nanjing, Zhenjiang, and Zhoushan; Shanghai and Jiaxing are also included. The extremely low and slightly low risk areas are concentrated in the south of the YRDR, especially in the southeast coastal area, Taizhou (Zhejiang province), Ningbo, Shaoxing, and Hangzhou, while the rest of the YRDR are medium risk areas.

Table 5 shows the statistics of the risk levels for drought in the YRDR cities. The relative risk level in most areas of Shanghai is slightly high $(68.59 \%)$ or extremely high $(26.47 \%)$. In the northern YRDR, the proportion of slightly high and extremely high risk areas in Nantong, Zhenjiang, Yangzhou, and Taizhou (Jiangsu province) is more than 95\%. The overall level of risk in Zhejiang province is lower than that in Jiangsu province especially in Hangzhou and Taizhou, where the proportion of slightly high and extremely high risk areas is below 5\%. The level of drought risk in Jiaxing and Zhoushan, where the proportions of slightly high 
TABLE 5: Statistics of risk levels of drought disasters in the YRDR.

\begin{tabular}{ccccccc}
\hline \multicolumn{2}{c}{$\begin{array}{c}\text { Administrative region } \\
\text { Provinces }\end{array}$} & Prefecture level city & Extremely low & Comprehensive risk level (area/percentage, km $\left.{ }^{2} / \%\right)$ \\
\hline Shanghai & - & $0.00 / 0.00$ & $3.07 / 0.05$ & $351.55 / 4.88$ & $4040.27 / 68.59$ & $1582.49 / 26.47$ \\
\hline & Nanjing & $7.17 / 0.11$ & $270.58 / 4.25$ & $1606.07 / 25.24$ & $3479.64 / 54.68$ & $1000.33 / 15.72$ \\
& Wuxi & $12.30 / 0.32$ & $354.63 / 9.09$ & $901.94 / 23.11$ & $897.84 / 23.00$ & $1736.23 / 44.49$ \\
& Changzhou & $0.00 / 0.00$ & $80.97 / 1.90$ & $788.17 / 18.45$ & $2722.21 / 63.72$ & $680.55 / 15.93$ \\
Jiangsu & Suzhou & $0.00 / 0.00$ & $112.74 / 1.79$ & $1081.30 / 17.19$ & $3822.99 / 60.76$ & $1275.01 / 20.26$ \\
& Nantong & $0.00 / 0.00$ & $0.00 / 0.00$ & $36.90 / 0.46$ & $2525.43 / 31.61$ & $5428.03 / 67.93$ \\
& Yangzhou & $0.00 / 0.00$ & $2.05 / 0.03$ & $223.43 / 3.45$ & $1402.10 / 21.67$ & $4842.79 / 74.85$ \\
& Zhenjiang & $0.00 / 0.00$ & $6.15 / 0.16$ & $193.71 / 5.04$ & $2004.76 / 52.17$ & $1637.84 / 42.62$ \\
& Taizhou & $0.00 / 0.00$ & $0.00 / 0.00$ & $23.57 / 0.42$ & $539.11 / 9.71$ & $4988.33 / 89.86$ \\
\hline & Hangzhou & $2985.62 / 18.32$ & $7283.15 / 44.68$ & $5906.67 / 36.24$ & $125.04 / 0.77$ & $0.00 / 0.00$ \\
& Ningbo & $2036.54 / 26.13$ & $3463.24 / 44.44$ & $1883.82 / 24.17$ & $351.55 / 4.51$ & $58.42 / 0.75$ \\
Zhejiang & $290.06 / 5.08$ & $2060.11 / 36.07$ & $2560.28 / 44.83$ & $762.55 / 13.35$ & $37.92 / 0.66$ \\
& Huzhou & $0.00 / 0.00$ & $16.40 / 0.42$ & $314.65 / 8.13$ & $2678.14 / 69.22$ & $859.92 / 22.23$ \\
& Jiaxing & $548.34 / 7.03$ & $3583.16 / 45.92$ & $2947.70 / 37.77$ & $722.58 / 9.26$ \\
$2.05 / 0.03$ \\
\end{tabular}
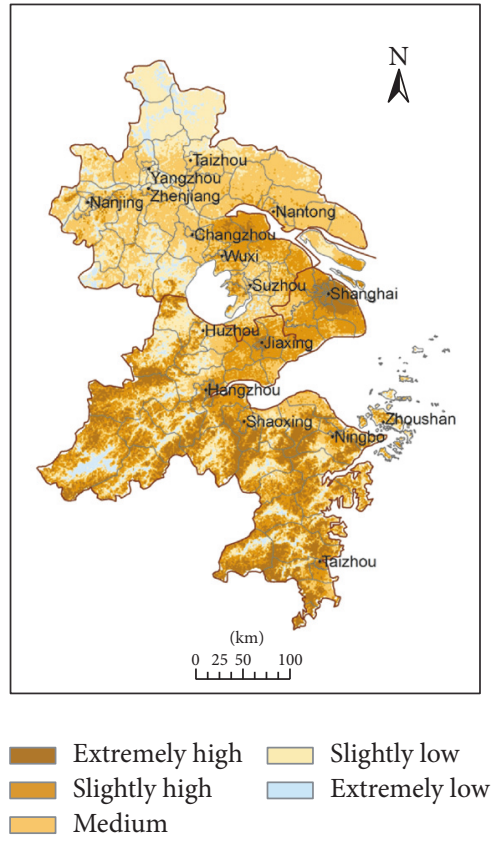

FIGURE 2: Distribution of drought vulnerability grades in the YRDR.

and extremely high risk areas are over $80 \%$, respectively, is relatively high compared with other cities in Zhejiang province.

\section{Conclusions}

Natural disaster risk assessment is applied to drought in the YRDR. Using this method, natural disaster risk is caused by hazard and vulnerability. The relative level of drought risk

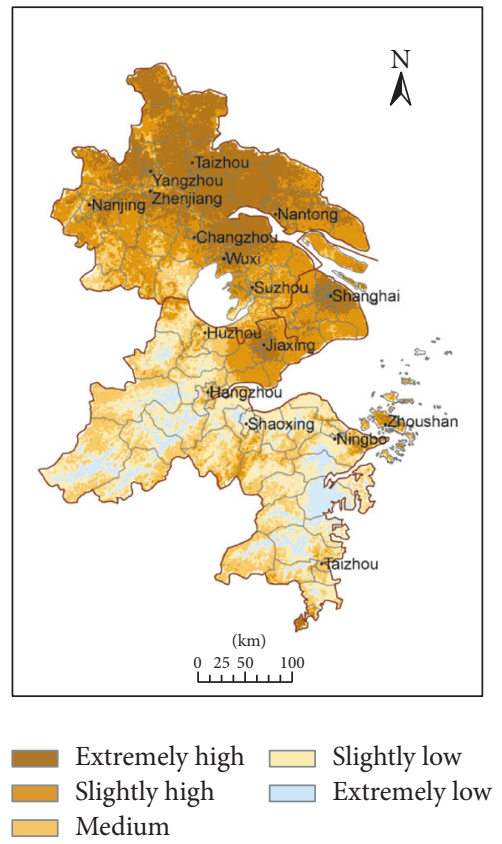

FIGURE 3: The risk distribution of drought in the YRDR.

zoning in the YRDR is achieved based on calculating the drought risk index.

There is high drought hazard in the north of the YRDR, while the coastal areas of Zhejiang face the lowest hazard. The higher drought vulnerability in the YRDR is mainly distributed in economically developed areas such as the southern part of Jiangsu, the northern part of Zhejiang, and Shanghai. Additionally, the northern part of the YRDR consists of the Yangtze River estuary plain, flat terrain, dense 
river network, and numerous lakes; the drought vulnerability is a little low overall. In contrast, the southern part of the YRDR is a mountainous region, where higher terrain and a sparse river network enhance the drought factor and increase the drought vulnerability.

The areas at extremely high risk for drought are mainly concentrated in the northern part of the YRDR, including Yangzhou and most parts of Taizhou (Jiangsu province). The slightly high risk areas are concentrated in Nanjing, Changzhou, Nantong, Zhoushan, Jiaxing, and Shanghai. The extremely low and slightly low risk areas are concentrated in the south of the YRDR, especially in the southeast coastal area, Taizhou (Zhejiang province), Shaoxing, and Hangzhou, while the rest of the YRDR are medium risk areas.

Building on the foundation of drought risk assessment, research and development regarding drought risk management systems are important issues for the future. At present, because of the lack of awareness of drought risk management, most departments focus on responses to disaster while ignoring disaster prevention. An important aspect of establishing a drought risk management system is to reduce drought losses; this approach integrates drought risk assessment, risk assessment, risk response strategy, and public risk awareness.

\section{Conflicts of Interest}

The authors declare that there are no conflicts of interest regarding the publication of this paper.

\section{Acknowledgments}

The research has been supported by the National Natural Science Foundation of China (Grant no. 41605049) and the National Science and Technology Support Program: research on the risk assessment technology of natural disasters in the YRDR (Grant no. 2008BAK50B07).

\section{References}

[1] IPCC (Intergovernmental Panel on Climate Change), Climate Change 2014: Impacts, Adaptation, and Vulnerability, Cambridge University Press, New York, NY, USA, 2014.

[2] J. Strutt, Risk Management Centre of Industrial Safety and Reliability, American Risk and Insurance Association, Grandfield University, 1999, http://www.aria.org/riskpos.htm.

[3] K. Wang, G.-L. Feng, Y.-X. Zeng, and X.-J. Wang, "Analysis of stable components in the extended-range forecast for the coming 10-30 days in winter 2010 and 2011," Chinese Physics B, vol. 22, no. 12, Article ID 129202, 2013.

[4] K. Hewitt, "Regions of Risk," Longman Singapore Publisher Ltd, 1997.

[5] A. Amendola, Y. Ermoliev, T. Y. Ermolieva, V. Gitis, G. Koff, and J. Linnerooth-Bayer, "A systems approach to modeling catastrophic risk and insurability," Natural Hazards, vol. 21, no. 2-3, pp. 381-393, 2000.

[6] R. Djalante, C. Holley, and F. Thomalla, "Adaptive governance and managing resilience to natural hazards," International Journal of Disaster Risk Science, vol. 2, no. 4, 2011.

[7] P. K. Das, S. Murthy C, and S. Mvr, "Monitoring of seasonal dryness/wetness conditions using shortwave angle slope index for early season agricultural drought assessment," Geomatics, Natural Hazards and Risk, vol. 5, no. 3, pp. 232-251, 2014.

[8] X. J. Liu, J. Q. Zhang, D. L. Ma, Y. L. Bao, Z. J. Tong, and X. P. Liu, "Dynamic risk assessment of drought disaster for maize based on integrating multi-sources data in the region of the northwest of Liaoning Province, China," Natural Hazards, vol. 65, no. 3, pp. 1393-1409, 2013.

[9] N. R. Dalezios, A. Blanta, N. V. Spyropoulos, and A. M. Tarquis, "Risk identification of agricultural drought for sustainable Agroecosystems," Natural Hazards and Earth System Sciences, vol. 14, no. 9, pp. 2435-2448, 2014.

[10] D. A. Wilhite, "Drought as a natural hazard: concepts and definitions," in Drought: A Global Assessment, A. Wilhite, Ed., Natural hazards and disasters series, pp. 3-18, Routledge, New York, NY, USA, Chapter Wilhite A edition, 2000.

[11] P. Blaikie, T. Cannon, I. Davis, and B. Wisner, At Risk: Natural Hazards, People's Vulnerability and Disasters, Routledge, London, UK, 1994.

[12] K. Wang, G. Feng, T. Ye, X. Wang, and P. Liu, “The variation characteristics of Asian surface temperature and precipitation in the early 21st century," Discrete Dynamics in Nature and Society, vol. 2016, Article ID 7929647, 2016.

[13] S. S. Mishra and R. Nagarajan, "Spatio-temporal drought assessment in Tel river basin using Standardized Precipitation Index (SPI) and GIS," Geomatics, Natural Hazards and Risk, vol. 2, no. 1, pp. 79-93, 2011.

[14] L. C. Botterill and M. J. Hayes, "Drought triggers and declarations: Science and policy considerations for drought risk management," Natural Hazards, vol. 64, no. 1, pp. 139-151, 2012.

[15] IPCC (Intergovernmental Panel on Climate Change), Climate Change 2013: The Physical Science Basis. Contribution of Working Group I to the Fifth Assessment Report of the Intergovernmental Panel on Climate Change, Cambridge University Press, New York, NY, USA, 2013.

[16] V. Blauhut, L. Gudmundsson, and K. Stahl, “Towards panEuropean drought risk maps: Quantifying the link between drought indices and reported drought impacts," Environmental Research Letters, vol. 10, no. 1, Article ID 014008, 2015.

[17] S. Jülich, "Development of a composite index with quantitative indicators for drought disaster risk analysis at the micro level," Human and Ecological Risk Assessment, vol. 21, no. 1, pp. 37-66, 2015.

[18] K. Strzepek, G. Yohe, J. Neumann, and B. Boehlert, "Characterizing changes in drought risk for the United States from climate change," Environmental Research Letters, vol. 5, no. 4, Article ID 044012, 2010.

[19] S. Shahid and H. Behrawan, "Drought risk assessment in the western part of Bangladesh," Natural Hazards, vol. 46, no. 3, pp. 391-413, 2008.

[20] W. C. Palmer, "Meteorological Drought," U.S. department of Commerce Weather Bureau Research Paper, 1965.

[21] W. C. Palmer, "Keeping track of crop moisture condition, nationwise: the new crop moisture index," Weatherwise, vol. 21, no. 4, pp. 156-161, 1968.

[22] M. J. Hayes, M. D. Svoboda, D. A. Wilhite, and O. V. Vanyarkho, "Monitoring the 1996 drought using the standardized precipitation index," Bulletin of the American Meteorological Society, vol. 80, no. 3, pp. 429-438, 1999.

[23] X.-C. Yuan, Y.-L. Zhou, J.-L. Jin, and Y.-M. Wei, "Risk analysis for drought hazard in China: A case study in Huaibei Plain," Natural Hazards, vol. 67, no. 2, pp. 879-900, 2013. 
[24] GB/T 20481-2006, Classification of Meteorological Drought, China Standards Press, 2006.

[25] X. N. Lu, J. Hong, and L. L. Wang, "Drought risk assessment in complex landform area," Transactions of the Chinese Society of Agricultural Engineering, vol. 31, no. 1, pp. 162-169, 2015.

[26] W. H. Cao, H. P. Tao, and B. Kong, "Automatic identification of geomorphology partition of Southwest China based on DEM data," in Soil and Water Conservation in China, vol. 3, pp. 38-41, 2011. 


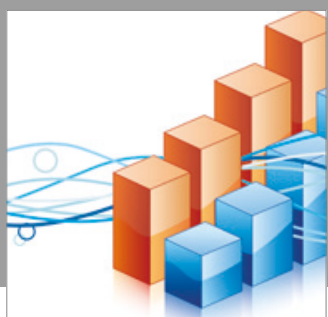

Advances in

Operations Research

vatersals

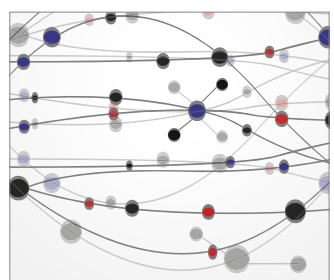

\section{The Scientific} World Journal
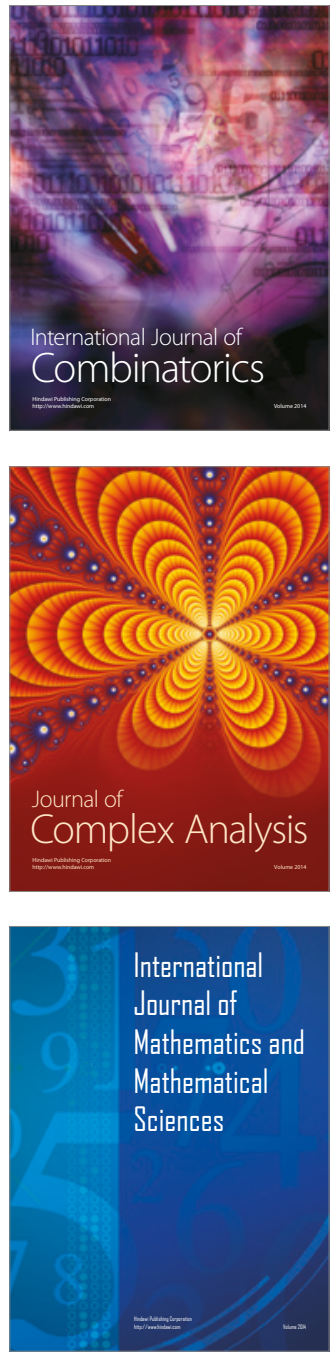
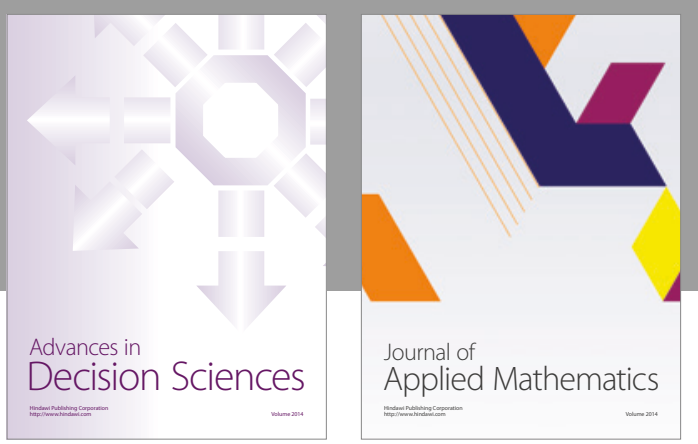

Algebra

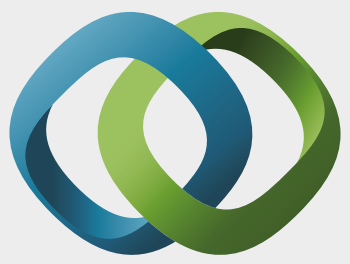

\section{Hindawi}

Submit your manuscripts at

https://www.hindawi.com
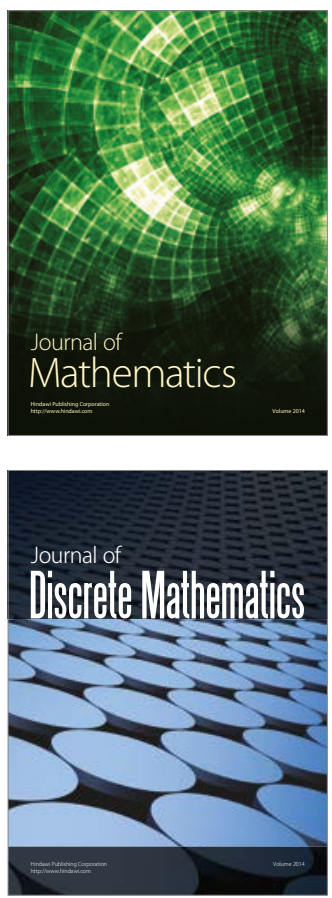

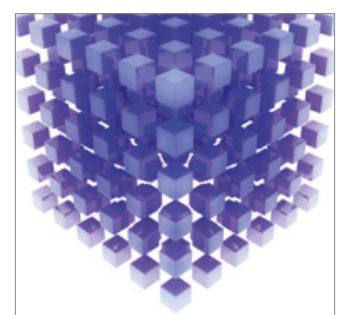

Mathematical Problems in Engineering
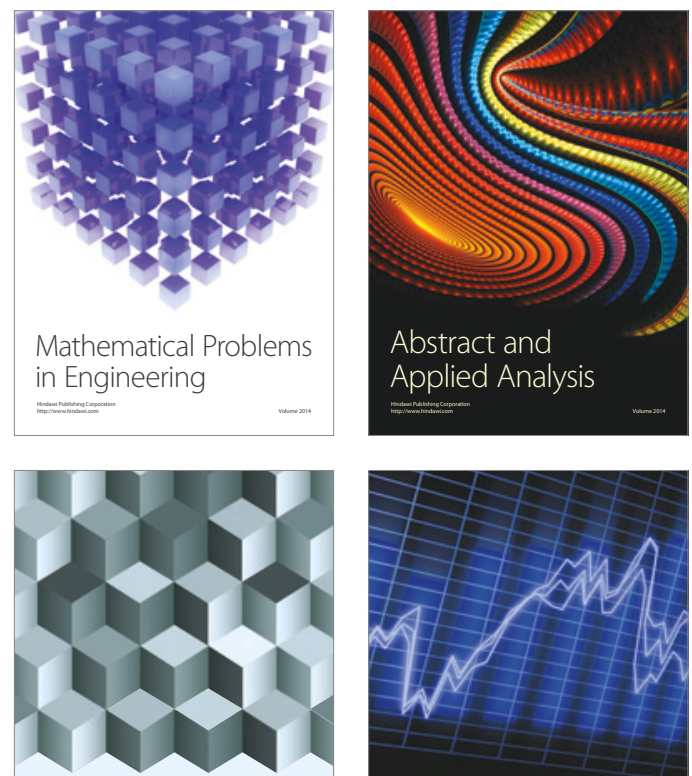

Journal of

Function Spaces

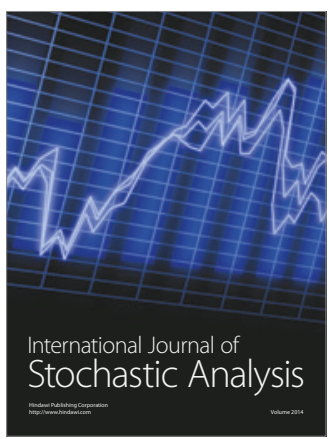

Probability and Statistics
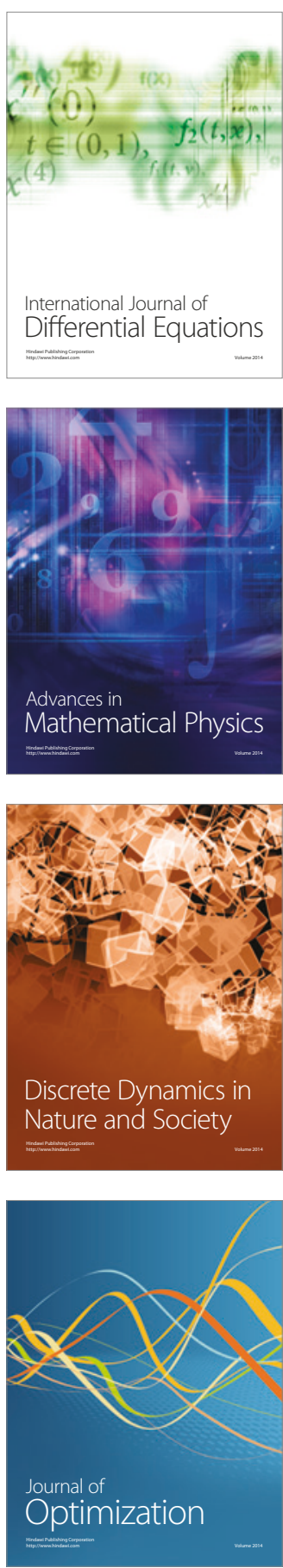